Research Paper

\title{
Phosphorylated Protein Kinase C (Zeta/Lambda) Expression in Colorectal Adenocarcinoma and Its Correlation with Clinicopathologic Characteristics and Prognosis
}

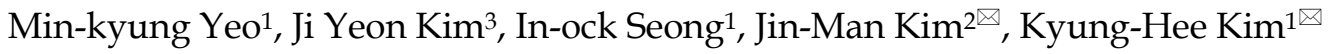 \\ 1. Department of Pathology, Cancer Research Institute, Chungnam National University School of Medicine, Daejeon, Republic of Korea; \\ 2. Department of Pathology and Medical Science, Chungnam National University School of Medicine, Daejeon, Republic of Korea; \\ 3. Department of Surgery, Chungnam National University Hospital, Daejeon, Republic of Korea.
}

$\square$ Corresponding authors: Kyung-Hee Kim, M.D., Ph.D. Department of Pathology, Cancer Research Institute, Chungnam National University School of Medicine, Munwha-ro 266, Jung-gu, Daejeon, Republic of Korea, 35015 Phone: 82-42-580-8238 Fax: 82-42-581-5233 E-mail: phone330@cnu.ac.kr and Jin-Man Kim, M.D., Ph.D. Department of Pathology and Medical Science, Chungnam National University School of Medicine, Munwha-ro 266, Jung-gu, Daejeon, Republic of Korea, 35015 Phone: 82-42-580-8237 Fax: 82-42-581-5233 E-mail: jinmank@cnu.ac.kr

( ) Ivyspring International Publisher. This is an open access article distributed under the terms of the Creative Commons Attribution (CC BY-NC) license (https://creativecommons.org/licenses/by-nc/4.0/). See http://ivyspring.com/terms for full terms and conditions.

Received: 2017.05.11; Accepted: 2017.08.29; Published: 2017.09.20

\begin{abstract}
Background: Protein kinase $C$ zeta/lambda $(\mathrm{PKC} \zeta / \lambda)$ is a family of protein kinase enzymes that contributes to cell proliferation and regulation, which are important for cancer development. PKC $\zeta / \lambda$ has been shown to be an important regulator of tumorigenesis in intestinal cancer. The phosphorylated form of PKC $\zeta / \lambda$, $\mathrm{p}-\mathrm{PKC} \zeta / \lambda$, is suggested as an active form of $P K C \zeta / \lambda$. However, $\mathrm{P}-\mathrm{PKC} \zeta / \lambda$ expression and its clinicopathologic implication in colorectal adenocarcinoma (CRAC) are unclear.

Methods: Seven whole-tissue sections of malignant polyps containing both non-neoplastic and neoplastic mucosa, 11 adenomas with low-grade dysplasia, and 173 CRACs were examined by immunohistochemistry and western blot assay for $\mathrm{p}-\mathrm{PKC} \zeta / \lambda$ protein expression. The association of $\mathrm{p}-\mathrm{PKC} / \lambda$ expression with clinicopathologic factors including patient survival was studied.

Results: In non-neoplastic epithelia, $\mathrm{p}-\mathrm{PKC} \zeta / \lambda$ showed a weak cytoplasmic immunostaining. Adenomas and CRACs demonstrated up-regulated p-PKC $\zeta / \lambda$ detection. Cytoplasmic $\mathrm{p}-\mathrm{PKC} \zeta / \lambda$ expression was higher in CRAC than in adenoma. In CRACs, $\mathrm{P}-\mathrm{PKC} Z / \lambda$ expression was inversely correlated with pathologic TNM stage (I-II versus III-IV) and poor differentiation. Statistical correlations between low expression of $\mathrm{p}-\mathrm{PKC} \zeta / \lambda$ with shortened overall survival and disease-free survival were seen $(p=0.004$ and $p=0.034$, respectively).

Conclusions: $\mathrm{P}-\mathrm{PKC} \zeta / \lambda$ overexpression is implicated in tumorigenesis but down-regulation was a poor prognostic factor in CRAC.
\end{abstract}

Key words: Protein kinase C zeta, protein kinase C lambda, colorectal adenocarcinoma.

\section{Introduction}

Protein kinase $\mathrm{C}$ (PKC) is a family of isoenzymes and comprises a complex of serine/threonine kinases, which are involved in signal transduction cascades. The PKC family is grouped into classical $(\alpha, \beta, \gamma)$, novel $(\delta, \varepsilon, \eta, \theta)$, and atypical $(\zeta, \lambda, \imath, \mu)$ based on their structures and activation chracteristics [1]. The last atypical PKC (aPKC) isoforms are independent of calcium $\left(\mathrm{Ca}^{2+}\right)$ and diacylglycerol (DAG) compared to other PKCs, which require $\mathrm{Ca}^{2}+$ or DAG for activation $[2,3]$. The aPKCs play a major role in the regulation of cell proliferation, apoptosis, survival, and cell polarity for the control of intracellular signaling $[4,5]$. 
Protein kinase $\mathrm{C}$ zeta/lambda (PKC $\zeta / \lambda$ ) belongs to the aPKC isoenzymes and is necessary for mitogenic signal transduction in a variety of cell types $[6,7]$. Recently, $\mathrm{PKC} \zeta / \lambda$ gained an attention for tumorigenesis and stemness in intestinal cancer $[8,9]$. $\mathrm{PKC} \zeta / \lambda$ exhibited an up-regulation in several cancers, including gastrointestinal tract cancers related with motility and invasiveness [10-13]. PKC $\zeta / \lambda$ was overexpressed in colon cell lines and showed clinicopathologic significance in colorectal adenocarcinoma (CRAC) [8, 14-16]. CRAC is the most common gastrointestinal cancer and a leading cause of cancer mortality in both men and women [17]. The survival rate for CRAC has increased substantially due to early cancer detection [18]. However, the development of recurrence or metastases occurs even after successful surgical treatment, and the 5-year survival rate is approximately $10 \%$ for patients with distant metastasis [18]. Identification of prognostic and therapeutic targets for CRAC is still required, and the $\mathrm{PKC} \zeta / \lambda$ has the potential to be a novel target for CRAC with clinical implications.

Because PKC is a family of protein kinase enzymes, PKCs participate in controlling the function of target proteins through phosphorylation of hydroxyl groups of serine/threonine amino acid [2]. PKC, itself, is also phosphorylated by enzymes and that is essential for the intracellular signaling requirement for activation of catalytic activity and translocation [19-21]. Thus far, little was known about phoshorylated-PKC $\zeta / \lambda \quad(\mathrm{p}-\mathrm{PKC} \zeta / \lambda)$ expression pattern and function in CRAC. To evaluate the role of $\mathrm{p}-\mathrm{PKC} \zeta / \lambda$ in CRAC, $\mathrm{p}-\mathrm{PKC} \zeta / \lambda$ and $\mathrm{PKC} \zeta$ protein expressions were measured. This study assessed $\mathrm{p}-\mathrm{PKC} \zeta / \lambda$ and $\mathrm{PKC} \zeta$ detections in non-neoplastic colonic epithelia, adenoma, and CRAC to evaluate differential expression during tumorigenesis. The $\mathrm{p}-\mathrm{PKC} \zeta / \lambda$ and $\mathrm{PKC} \zeta$ expressions were analyzed to find the relationship of clinicopathologic features including patient survival in CRAC.

\section{Materials and Methods}

\section{Patients and specimens}

A total of 173 patients underwent curative surgical treatment and were histologically diagnosed with CRAC. Information of the patients and survival were collected from medical records. None of the patients had received pre-operative chemotherapy or radiotherapy. CRAC stages were determined according to the American Joint Committee on Cancer Staging System, seventh edition [22]. All cases were clinicopathologically reviewed by two pathologists (MKY and KHK).

The 173 paraffin-embedded colorectal samples of patients were obtained from Chungnam national university hospital, Daejeon, South Korea, between 2002 and 2015. Two most representative and viable neoplastic and non-neolastic tissue areas were selected and marked on the hematoxylin and eosin-stained slides. To create a tissue microarray, tissue columns ( $3.0 \mathrm{~mm}$ in diameter) were punched from the original paraffin blocks and inserted into new recipient paraffin blocks (each containing 30 holes for tissue columns). Seven whole tissue samples of malignant polyp containing the sequence non-neoplastic colorectal tissue-adenoma-CRAC and 11 colorectal adenoma with low-grade dysplasia samples were evaluated. All specimens were provided by national biobank of Korea, Chungnam national university hospital, a member of the Korea biobank network. This study was approved by the Institutional Review Board of Chungnam national university hospital (CNUH 2016-04-038).

\section{Immunohistochemical staining analysis}

Tissue sections on microslides were deparaffinized with xylene and hydrated in graded alcohol series. The sections were heated in a pressure cooker containing $10 \mathrm{mmol} / \mathrm{L}$ sodium citrate ( $\mathrm{pH}$ 6.0) for $3 \mathrm{~min}$ at full power for antigen retrieval. Endogenous peroxidase activity blocking was performed using $0.03 \%$ hydrogen peroxide containing sodium azide for $5 \mathrm{~min}$. The sections were incubated at room temperature for 1 hour with the rabbit monoclonal anti-p-PKC $\zeta / \lambda$ (phosphorylated at T410 for PKC $\zeta$ and phosphorylated at T412 for PKC $\lambda$ ) antibody (1:200, ab76129, Abcam, Cambridge, United Kingdom) and with the rabbit polyclonal anti-PKC $\zeta$ antibody (C-20) (1:300, sc-216, Santa Cruz Biotechnology, Santa Cruz, CA, US). After washing, the samples were incubated in labelled polymer-HRP anti-mouse (Dako EnVision+system-HRP (DAB), Dako, Carpinteria, California, USA) for an additional $20 \mathrm{~min}$ at room temperature followed by additional washing. After rinsing, chromogen was developed for $2 \mathrm{~min}$. The slides were then counterstained with Meyer's hematoxylin, dehydrated, and coverslipped. The primary antibody was omitted in the negative controls.

Immunohistochemical staining was scored using digitally scanned files by a scanscope program (Aperio ScanScope CS system, Vista, CA, USA) and using a light microscope. The Allred et al. method was used to evaluate both intensity of immunohistochemical staining and proportion of stained tumor cells or non-neoplastic mucosal epithelial cells in each stained slide. The proportion score (range: $0-5$ ) and intensity score (range: $0-3$ ) were added to obtain the total score (range: 0-8) [23]. Ten 
low power fields ( $\times 100$ magnification) were examined and scored for mean value. The total score was graded as low (total score; less than that of non-neoplastic epithelia) or high (total score; greater than that of non-neoplastic epithelia). Each sample was examined separately and scored by two pathologists (MKY and KHK). Discrepancies in scores were discussed to obtain a consensus.

\section{Western blot assay}

Proteins were extracted from 40 pairs of CRAC sample and non-neoplastic tissue sample stored at $-80^{\circ} \mathrm{C}$ in liquid nitrogen using PRO-PREP TM protein extraction solution (iNtRON Biotechnology, 17081, Kyungki-do, South Korea). A total $20 \mu \mathrm{g}$ of protein was separated using 10\% sodium dodecyl sulfate (SDS)-polyacrylamide gel electrophoresis (BIO-RAD®, Mini-PROTEAN TGXTM Gels, 456-1034, California, USA) and then electophoretically transferred to polyvinylidene difluoride (PVDF) membrane (BIO-RAD, Immun-Blot ${ }^{\circledR} \quad$ PVDF Membrane for Protein Blotting, 162-0177, California, USA). The membrane was blocked with $2 \%$ dry skim milk and incubated with the rabbit monoclonal anti-p-PKC $\zeta / \lambda$ (1:1000, ab76129, Abcam, Cambridge, United Kingdom) and $\beta$-actin (1:1,000; Cell Signaling Tech Inc.) antibodies. After washing, the membrane was incubated in goat anti-rabbit IgG, and H\&L chain-specific peroxidase conjugate secondary antibody (CALBIOCHEM, 401353, Darmstadt, Germany) at room temperature for 1 hour. Protein bands were enhanced by Immobilon ${ }^{\circledR}$ western chemiluminescent HRP substrate (Millipore, WBKLS0500, USA) and the images were digitalized using an UVITEC Cambridge alliance mini $4 \mathrm{M}$ system (UVItec Limited, Cambridge, UK). The tissue sample was omitted in the negative control. Human colonic adenocarcinoma cell line COLO320HSR (KCLB 10020.1) was used as positive control. The $\mathrm{p}-\mathrm{PKC} \zeta / \lambda$ and $\beta$-actin bands were quantified by Image $J$ program (https://imagej.nih.gov/ij/notes.html). The relative quantification value of $\mathrm{p}-\mathrm{PKC} \zeta / \lambda$ in each tissue sample was presented as a ratio of their $\mathrm{p}-\mathrm{PKC} \zeta / \lambda$ band value to that of $\beta$-actin band value. The total $p-P K C \zeta / \lambda$ band value was graded as low (less than that of paired non-neoplastic epithelia value) or high (greater than that of paired non-neoplastic epithelia value).

\section{Statistical analysis}

Associations of $\mathrm{p}-\mathrm{PKC} \zeta / \lambda$ and $\mathrm{PKC} \zeta$ immunohistochemical expressions, and $\mathrm{p}-\mathrm{PKC} \zeta / \lambda$ western blot expression with clinicopathologic variables for the colorectal neoplastic lesions were examined with Spearman rank correlation coefficient,
Mann-Whitney U-test, and Kruskal-Wallis test. Correlation coefficients were calculated using the Spearman rank method. Overall survival and disease-free survival curves were determined using the Kaplan-Meier method. Univariate and multivariate survival analyses were assessed using log-rank test and Cox's proportional hazard regression model, respectively. Statistical significance was set at $\mathrm{p}<0.05$ (SPSS 22; SPSS Inc., Chicago, IL, USA).

\section{Results}

\section{Differential immunohistochemical expression of $\mathrm{p}-\mathrm{PKC} \zeta / \mathrm{A}$ and $\mathrm{PKC} \zeta$ in non-neoplastic, adenoma, and CRAC}

P-PKC $\zeta$ and PKC $\zeta$ immunostaining were detected in colonic epithelial cells, but not in stromal cells. P-PKC $/ \lambda$ - and PKC $\zeta$-stained cells exhibited cytoplasmic pattern without nuclear or membranous pattern. The cytoplasmic $\mathrm{p}-\mathrm{PKC} \zeta / \lambda$ and $\mathrm{PKC} \zeta$ expressions were evaluated in the 7 whole-tissue sections of malignant polyps containing both non-neoplastic and neoplastic mucosa, 11 adenomas with low-grade dysplasia, and tissue microarray paraffin blocks containing 173 CRAC samples. All non-neoplastic epithelia were negative or weak stained for $\mathrm{p}-\mathrm{PKC} \zeta / \lambda$ and $\mathrm{PKC} \zeta$. Adenomas and microinvasive adenocarcinomas showed up-regulated p-PKC $\zeta / \lambda$ and $P K C \zeta$ expression (Fig. 1). Cytoplasmic detections of $\mathrm{p}-\mathrm{PKC} \zeta / \lambda$ and $\mathrm{PKC} \zeta$ were compared between adenoma and CRAC. CRAC showed significantly higher levels of $p-P K C \zeta / \lambda$ and $P K C \zeta$ expression than did the adenomas ( $p=0.000$ and $\mathrm{p}=0.006$, respectively).

\section{Clinicopathologic features and p-PKC $\zeta / \lambda$ and $P K C \zeta$ immunohistochemical expression patterns in CRAC}

A total of 173 CRAC samples with clinicopathologic features were investigated. Patients' age ranged from 25 to 89 years, with a mean of 61.9 years. CRACs were located in the ascending colon $(n=29)$, transverse colon $(n=9)$, descending colon $(n=7)$, sigmoid colon $(n=55)$, and rectum $(n=73)$. $\mathrm{P}-\mathrm{PKC} \zeta / \lambda$ and PKC $\zeta$ expression of CRACs was positively correlated with each other $(p=0.000)$. $\mathrm{P}-\mathrm{PKC} \zeta / \lambda$ expression was negatively correlated with pathologic stage (I-II vs. III-IV), poorly differentiated CRAC (including the mucinous type), radiation therapy, and chemotherapy $(p=0.039, p=0.002$, $p=0.002$, and $p=0.009$, respectively). $P K C \zeta$ expression was negatively correlated with poorly differentiated CRAC (including the mucinous type) and radiation therapy ( $p=0.004$ and $p=0.002$, respectively) (Table 1 ). 

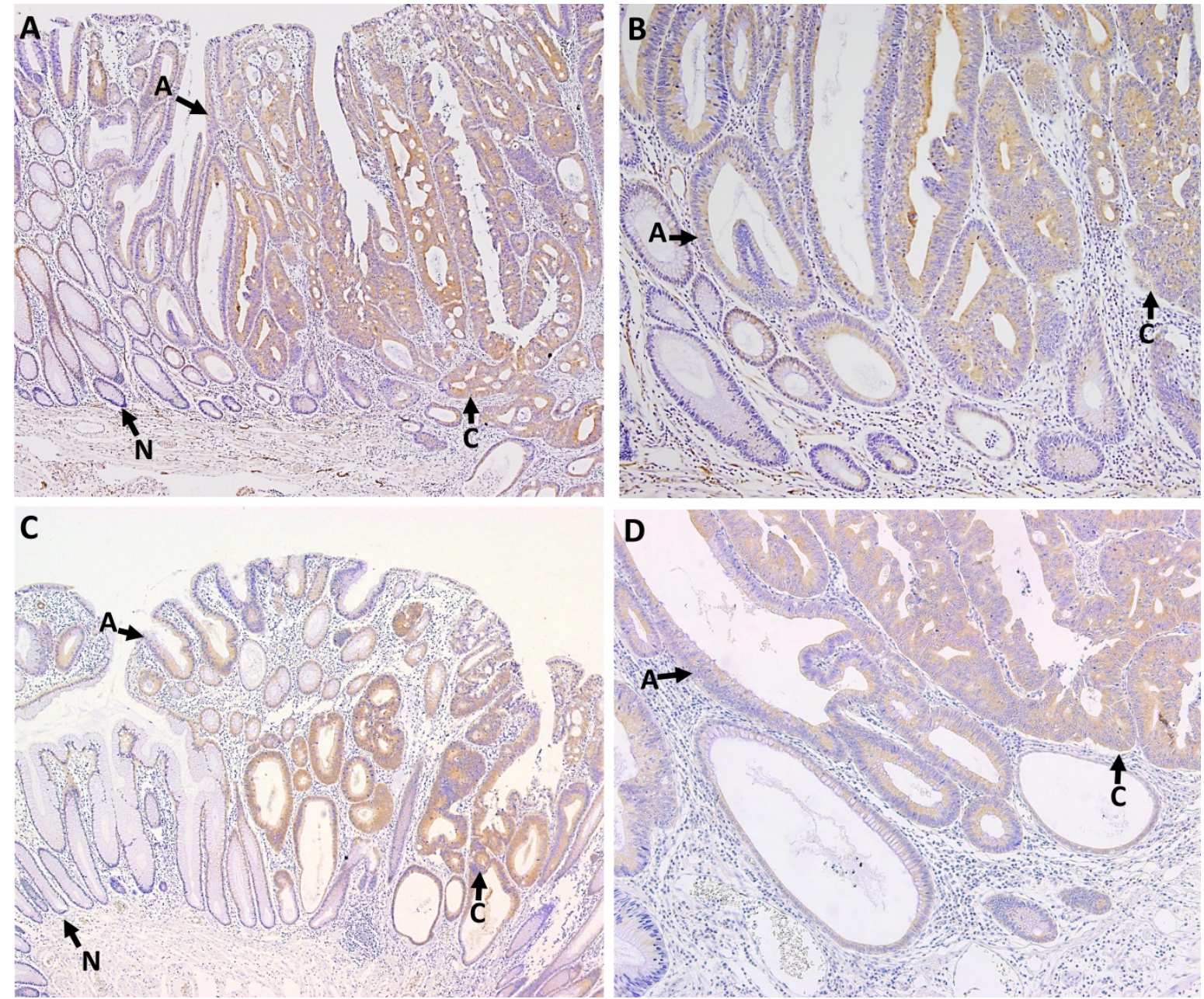

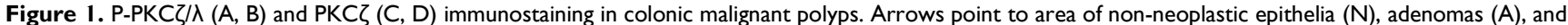
carcinomas (C). Non-neoplastic epithelia showed negative or weak cytoplamic expression of p-PKC $/ \lambda$ and PKC . Adenomas and microinvasive adenocarcinomas were up-regulated. Adenocarcinomas exhibited higher $\mathrm{p}-\mathrm{PKC} \zeta / \lambda$ and $\mathrm{PKC} \zeta$ expression than adenomas $(\mathrm{A} ; \mathrm{p}-\mathrm{PKC} / \lambda \times 100, \mathrm{~B} ; \mathrm{p}-\mathrm{PKC} / / \lambda \times 200, \mathrm{C} \mathrm{PKC \zeta} \times 100$, and D; PKC $\zeta \times 200)$.

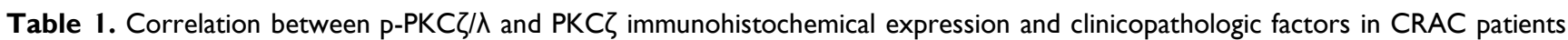
$(n=173)$.

\begin{tabular}{|c|c|c|c|c|c|c|c|c|}
\hline \multirow[t]{2}{*}{ Characteristics } & \multicolumn{2}{|l|}{ Patients } & \multicolumn{2}{|c|}{$\mathrm{p}-\mathrm{PKC \zeta} / \lambda$} & \multicolumn{2}{|l|}{ Patients } & \multicolumn{2}{|l|}{ 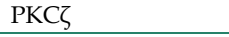 } \\
\hline & No. (\%) & Low & High & $\mathrm{P}$ & No. $(\%)$ & Low & High & $\mathrm{P}$ \\
\hline Sex & & & & 0.450 & & & & 0.503 \\
\hline Male & 109 & $13(72)$ & $96(62)$ & & 108 & $10(71)$ & $98(62)$ & \\
\hline Female & 64 & $5(28)$ & $59(38)$ & & 63 & $4(29)$ & $59(38)$ & \\
\hline Age (mean) & 173 & 56 & 63 & 0.018 & 171 & 59 & 62 & 0.331 \\
\hline Tumor size (mean, cm) & 173 & 4.6 & 4.8 & 0.715 & 171 & 4.2 & 4.7 & 0.362 \\
\hline Differentiation & & & & 0.002 & & & & 0.004 \\
\hline WD+MD & 158 & $13(72)$ & $145(94)$ & & 157 & $10(71)$ & $147(94)$ & \\
\hline PD+mucinous & 15 & $5(28)$ & $10(7)$ & & 14 & $4(28)$ & $10(6)$ & \\
\hline Nodal metastasis & & & & 0.104 & & & & 0.909 \\
\hline Absent & 89 & $6(33)$ & $83(54)$ & & 88 & $7(50)$ & $81(52)$ & \\
\hline Present & 84 & $12(67)$ & $72(47)$ & & 83 & $7(50)$ & $76(48)$ & \\
\hline Pathologic stage & & & & 0.039 & & & & 0.865 \\
\hline I-II & 78 & $4(22)$ & $74(48)$ & & 77 & $6(43)$ & $71(45)$ & \\
\hline III-IV & 95 & $14(78)$ & $81(52)$ & & 94 & $8(57)$ & $86(55)$ & \\
\hline Radiotherapy & & & & 0.002 & & & & 0.002 \\
\hline Not done & 153 & $12(67)$ & $141(91)$ & & 152 & $9(64)$ & $143(91)$ & \\
\hline Done & 20 & $6(33)$ & $14(9)$ & & 19 & $5(36)$ & $14(9)$ & \\
\hline Chemotherapy & & & & 0.009 & & & & 0.974 \\
\hline Not done & 98 & $5(28)$ & $93(60)$ & & 97 & $8(57)$ & $89(57)$ & \\
\hline Done & 75 & $13(72)$ & $62(40)$ & & 74 & $6(43)$ & $68(43)$ & \\
\hline
\end{tabular}

WD, well differentiated; MD, moderately differentiated; PD, poorly differentiated. 
Both overall survival and disease-free survival analyses were performed with data from 173 patients with CRAC. The Kaplan-Meier survival curves and log-rank tests showed significant association of $\mathrm{p}-\mathrm{PKC} \zeta / \lambda$-low expression with shortened overall and disease-free survivals $(p=0.005$ and $p=0.002$, respectively) (Fig. 2). The Kaplan-Meier overall and disease-free survival curves of low expression of PKC $\zeta$ showed a tendency of shortened survival times but did not attain statistical significance in either case $(\mathrm{p}=0.497$ and $\mathrm{p}=0.520$, respectively). The multivariate analyses using the Cox's proportional hazard model were performed on age, sex, stage (I-II vs. III-IV), and $\mathrm{p}-\mathrm{PKC} \zeta / \lambda$ expression. The multivariate analysis showed $\mathrm{p}-\mathrm{PKC} \zeta / \lambda$-low expression to be a significant prognostic factor indicative of poor overall and disease-free survival $(\mathrm{p}=0.004$ and $\mathrm{p}=0.034$, respectively) (Table 2). The multivariate analysis using the Cox's proportional hazard model was performed on age, sex, stage (I-II vs. III-IV), and PKC了 expression; statistical significance for overall and disease-free survival $(p=0.709$ and $p=0.805$, respectively) was not attained.

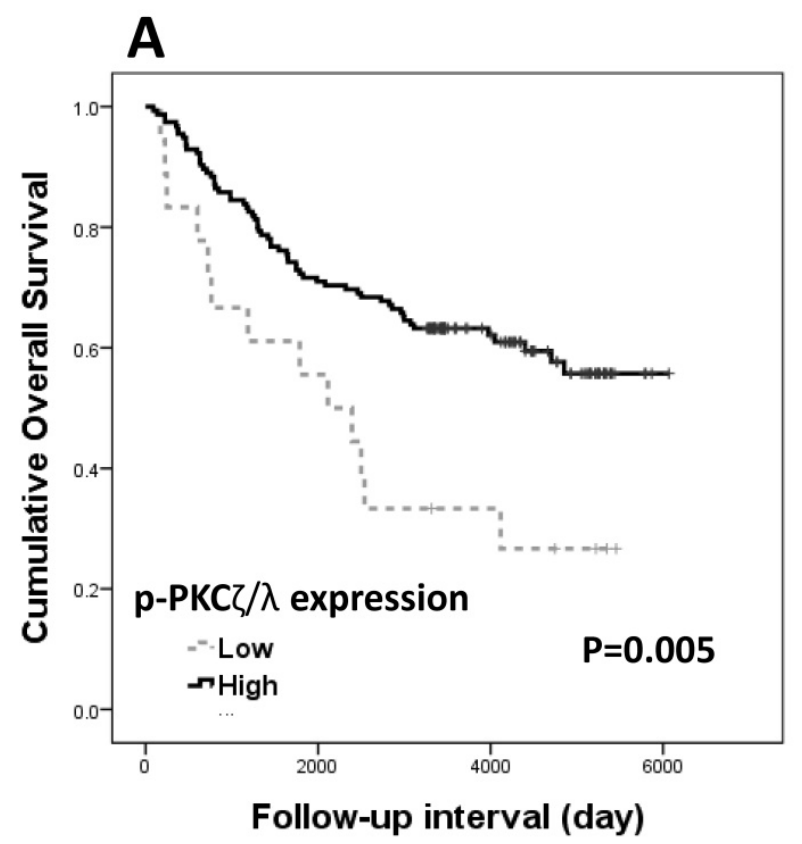

\section{Western blot assay of p-PKC $\zeta / \lambda$ expression and correlation with clinicopathologic features in CRAC}

P-PKC $\zeta / \lambda$ western blot assay showed that CRAC expressed a significantly higher level of $\mathrm{p}-\mathrm{PKC} \zeta / \lambda$ than did the non-neoplastic epithelia $(p=0.001)$ (Fig. 3). P-PKC $\zeta / \lambda$ western blot expression was negatively correlated with poorly differentiated CRAC (including the mucinous type) $(\mathrm{p}=0.012)$ and showed a tendency of negative correlation with chemotherapy $(p=0.054) \quad$ (Supplementary Table 1). Both overall survival and disease-free survival analyses were performed on data from 40 patients with CRAC. Kaplan-Meier overall and disease-free survival curves of $\mathrm{p}-\mathrm{PKC} \zeta / \lambda$-low expression showed a tendency of shortened survival times but did not attain statistical significance $(\mathrm{p}=0.514$ and $\mathrm{p}=0.120$, respectively) (Supplementary Fig.1). The multivariate analysis using the Cox's proportional hazard model was performed on age, sex, stage (I-II vs. III-IV), and p$\mathrm{PKC} \zeta / \lambda$ expression and it did not attain statistical significance for overall and disease-free survival $(\mathrm{p}=0.819$ and $\mathrm{p}=0.193$, respectively) (Supplementary Table 2).

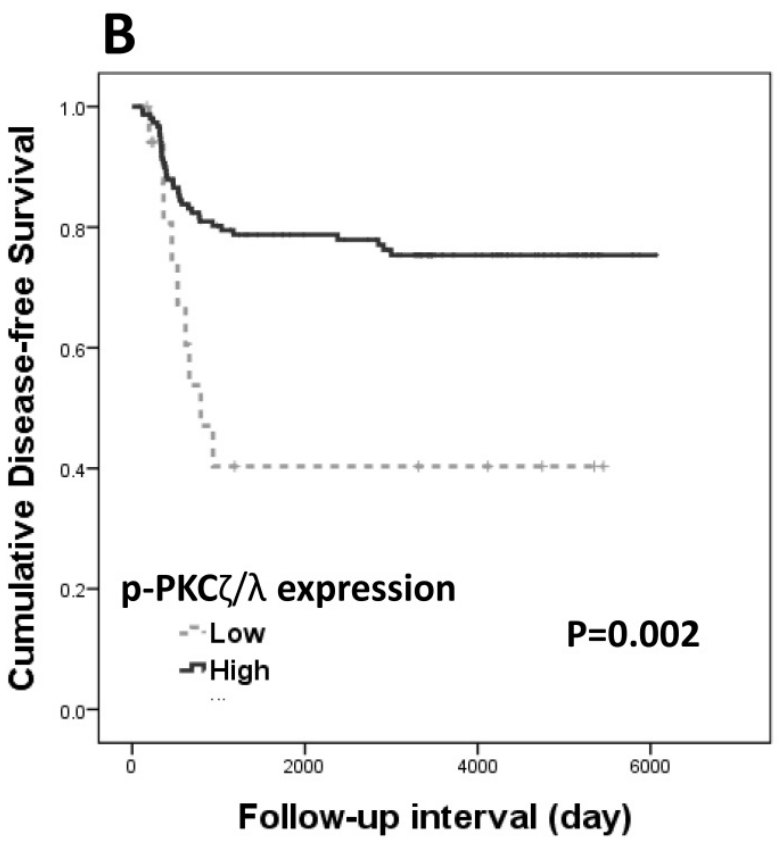

Figure 2. Kaplan-Meier survival curves according to $p-P K C \zeta / \lambda$ expression in $C R A C(n=173)$ : $(A)$ overall survival $(P=0.005)$ and $(B)$ disease-free survival $(p=0.002)$.

Table 2. Multivariate analysis results of overall survival and disease-free survival in CRAC patients $(n=170)$.

\begin{tabular}{|c|c|c|c|c|c|c|}
\hline & \multicolumn{3}{|c|}{ Overall survival } & \multicolumn{3}{|c|}{ Disease-free survival } \\
\hline & $\mathrm{p}$ & HR & $95 \% \mathrm{CI}$ & $\mathrm{p}$ & HR & $95 \% \mathrm{CI}$ \\
\hline P-PKC $\zeta / \lambda$ (low vs. high) & 0.004 & 0.395 & $(0.208-0.749)$ & 0.034 & 0.436 & $(0.203-0.937)$ \\
\hline Sex (male vs. female) & 0.355 & 0.794 & $(0.487-1.294)$ & 0.114 & 1.621 & $(0.890-2.953)$ \\
\hline Age (under 60 vs. over 60 ) & 0.008 & 2.001 & $(1.198-3.343)$ & 0.198 & 0.670 & $(0.364-1.2336)$ \\
\hline Stage (I+II vs. III+IV) & 0.021 & 2.395 & $(1.140-5.029)$ & 0.015 & 5.838 & $(1.400-24.340)$ \\
\hline
\end{tabular}

CRAC, colorectal adenocarcinoma; $\mathrm{HR}$, hazard ratio; $\mathrm{CI}$, confidence interval. 

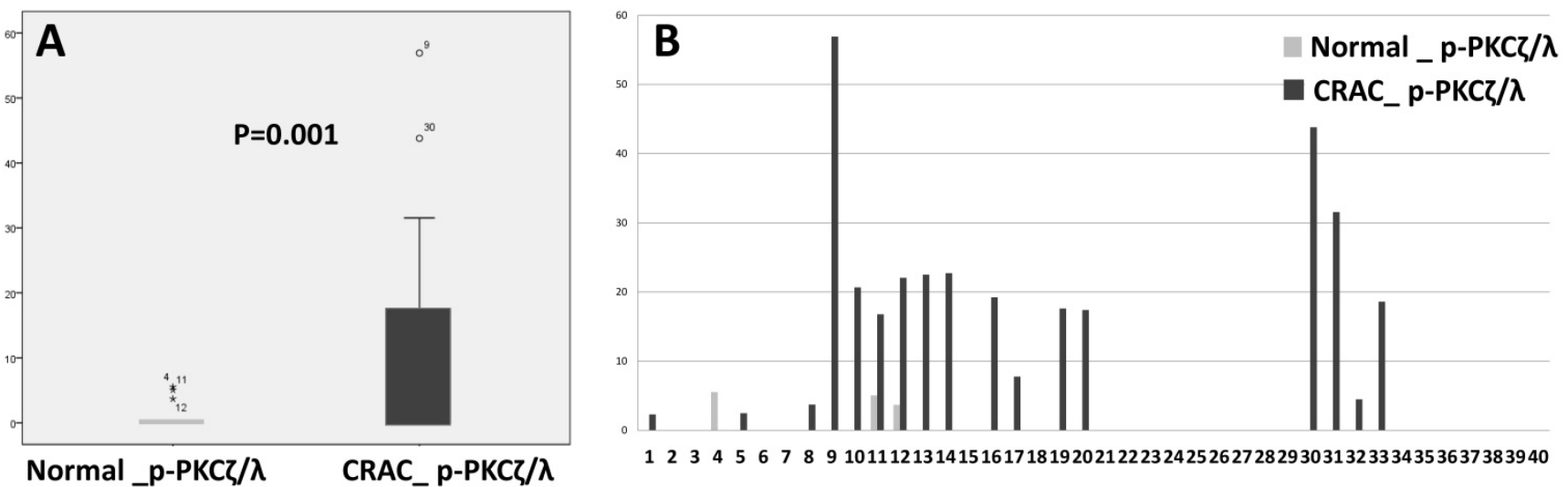

Figure 3. Comparison of expression detected by western blot assay between normal colonic epithelia and CRAC (Mann-Whitney test: $p=0.001, A)$. CRAC showed higher $\mathrm{P}-\mathrm{PKC} \zeta / \lambda$ expression than normal epithelia (B).

\section{Discussion}

The PKC family has been investigated in cancers since it was first found to be activated by phorbol-esters, which promote carcinogen-induced tumorigenesis [3]. $\mathrm{PKC \zeta} / \lambda$, an atypical subtype of the PKC family, has been shown to have an important regulatory effect on tumorigenesis [9, 24]. Interestingly, $\mathrm{PKC} \zeta / \lambda$ expression exhibits both tumor suppressive and tumor promoting functions in cancers $[25,26]$. The role of $\mathrm{p}-\mathrm{PKC} \zeta / \lambda$, an active form of $\mathrm{PKC} \zeta / \lambda$, in cancers has yet to be determined. The present study is the first to validate $\mathrm{p}-\mathrm{PKC} \zeta / \lambda$ expression in the CRAC. To assess $\mathrm{p}-\mathrm{PKC} \zeta / \lambda$ expression, both immunohistochemistry and western blot assay were performed in the CRACs. CRACs and adenomas showed more up-regulation of $\mathrm{p}-\mathrm{PKC} \zeta / \lambda$ and $P K C \zeta$ in immunostaining than did the non-neoplastic epithelia. Western blot assay for $\mathrm{P}-\mathrm{PKC} \zeta / \lambda$ detected a higher level of $\mathrm{p}-\mathrm{PKC} \zeta / \lambda$ in CRAC than in non-neoplastic epithelia. CRACs exhibited significantly up-regulated $\mathrm{p}-\mathrm{PKC} \zeta / \lambda$ and $\mathrm{PKC} \zeta$ detections than did the adenomas. From these results, $\mathrm{p}-\mathrm{PKC} \zeta / \lambda$ and $\mathrm{PKC} \zeta$ aberrant protein expression might be involved in colonic tumorigenesis and carcinogenesis.

Evidence from previous studies indicated that PKC $\zeta$ was as a key regulator of critical intracellular signaling pathways and activated Wnt-induced glycogen synthase kinase-3, which increases gene transcription in colon cancer cell lines [15, 21, 27]. However, $\mathrm{PKC} \zeta$ protein expression patterns showed conflicting results wherein up- or down-regulation was shown in CRACs $[15,25]$. PKC $\lambda$ expression was up-regulated in CRAC compared with the non-neoplastic epithelia $[9,16]$. PKC $\zeta / \lambda$ protein expression was increased in the carcinogen-induced colonic mucosa [28]. P-PKC $\zeta / \lambda$ was detected in the non-small cell lung cancer cell line, but little is known about its relationship with cancers [29].

The clinical implications of $\mathrm{p}-\mathrm{PKC} \zeta / \lambda$ and $\mathrm{PKC} \zeta$ protein expression were evaluated in this study. $\mathrm{P}-\mathrm{PKC} \zeta / \lambda$ immunostaining expression was inversely correlated with pathological stage and poor differentiation, and $\mathrm{PKC} \zeta$ expression was inversely correlated with poor differentiation. Considering multivariate and univariate survival analyses, p-PKC $\zeta / \lambda$ protein expression demonstrated a prognostic impact on CRAC. Studies on the relationship between $\mathrm{PKC} \zeta / \lambda$ expressions and its clinical significances in cancers have been undertaken. Low immunohistochemical expression of PKC $\zeta$ showed shortened disease-free survival in CRAC [8, 14]. The prognostic significance of $P K C \zeta$ was different depending on the type of cancers; Low expression of PKC $\zeta$ was related to unfavorable clinicopathologic parameters in prostate cancer, [30] whereas, high expression of $\mathrm{PKC} \zeta$ was associated with a worse patient survival in breast and renal cancers [31, 32]. High expression of PKC $\lambda$ was associated with a poor prognosis in stomach and lung cancers $[33,34]$.

Interestingly, $\mathrm{p}-\mathrm{PKC} \zeta / \lambda$ protein expression was shown to be a better prognostic marker than $P K C \zeta$ in the patients with CRAC in this study. The mechanisms of PKC activation are known to consist of two events: the release of the pseudosubstrate from the substrate-binding cavity and phosphorylation of the kinase domain [35]. PKC $\zeta$ is activated by phosphatidylinositols-3,4,5-trisphosphate (PIP3) and 3'-PI-dependent protein kinase 1 (PDK1) [21]. PDK1 interacts with $\mathrm{PKC \zeta}$ and phosphorylates the kinase domain at threonine-410 and then interacts with PIP3 to create stable activation. Sequential increase in $\mathrm{PKC \zeta}$ and p-PKC $\zeta$ expressions was observed in normal, dysplastic, and malignant squamous cell carcinoma of the head and neck (SCCHN) tissues and p-PKC was suggested to be a measurement of activity in SCCHN [36]. 
In conclusion, the up-regulation of cytoplasmic $\mathrm{p}-\mathrm{PKC} \zeta / \lambda$ and $\mathrm{PKC} \zeta$ protein expression in CRAC occurs at the time of malignant transformation; however, the down-regulation of cytoplasmic $\mathrm{p}-\mathrm{PKC} \zeta / \lambda$ and $\mathrm{PKC \zeta}$ expression in CRAC is associated with worse clinicopatholgic features in CRAC. Especially, down-regulated $\mathrm{p}-\mathrm{PKC} \zeta / \lambda$ has a prognostic impact on patient survival in CRAC. The roles of $\mathrm{p}-\mathrm{PKC} \zeta / \lambda$ and $\mathrm{PKC} \zeta$ are variable depending on the cell types and their clinical implications are still unclear. Further investigation of the underlying mechanism of $\mathrm{p}-\mathrm{PKC} \zeta / \lambda$ activation and the related signal pathway in CRAC are necessary.

\section{Abbreviations}

PKC: protein kinase C; aPKC: atypical protein kinase C; $\mathrm{Ca}^{2+}$ : calcium; DAG: diacylglycerol; $\mathrm{PKC} \zeta / \lambda$ : protein kinase $C$ zeta/lambda; CRAC: colorectal adenocarcinoma; $\quad \mathrm{p}-\mathrm{PKC} \zeta / \lambda$ : phoshorylated-protein kinase C zeta/lambda; PIP3: phosphatidylinositols-3,4,5-trisphosphate; PDK1: 3'-PI-dependent protein kinase 1; SCCHN: squamous cell carcinoma of the head and neck.

\section{Supplementary Material}

Supplementary figures and
http://www.jcancer.org/v08p3371s1.pdf

\section{Acknowledgment}

This work was supported by the Basic Science Research Program through the National Research Foundation of Korea (NRF) funded by the Ministry of Education, Science, and Technology (NRF-2016R1D1A1B01014311) and the Korean Health Technology R\&D Project, Ministry of Health \& Welfare (HI15C0789).

\section{Competing Interests}

The authors have declared that no competing interest exists.

\section{References}

1. Kang J-H. Protein kinase C (PKC) isozymes and cancer. New J Sci. 2014.

2. Griner EM, Kazanietz MG. Protein kinase $C$ and other diacylglycerol effectors in cancer. Nat Rev Cancer. 2007; 7: 281-94.

3. Castagna M, Takai Y, Kaibuchi K, et al. Direct activation of calcium-activated, phospholipid-dependent protein kinase by tumor-promoting phorbol esters. J Biol Chem. 1982; 257: 7847-51.

4. Khursheed M, Bashyam MD. Apico-basal polarity complex and cancer. J Biosci. 2014; 39: 145-55.

5. Fields AP, Regala RP. Protein kinase C iota: human oncogene, prognostic marker and therapeutic target. Pharmacol Res. 2007; 55: 487-97.

6. Berra E, Diaz-Meco MT, Dominguez I, et al. Protein kinase $\mathrm{C} \zeta$ isoform is critical for mitogenic signal transduction. Cell. 1993; 74: 555-63.

7. Suzuki A, Akimoto K, Ohno S. Protein kinase C lambda/iota (PKClambda/iota): a PKC isotype essential for the development of multicellular organisms. J Biochem. 2003; 133: 9-16.

8. Llado V, Nakanishi Y, Duran A, et al. Repression of intestinal stem cell function and tumorigenesis through direct phosphorylation of $\beta$-Catenin and Yap by PKC . Cell reports. 2015; 10: 740-54.
9. Murray NR, Weems J, Braun U, et al. Protein kinase $\mathrm{C}$ betall and PKCiota/lambda: collaborating partners in colon cancer promotion and progression. Cancer Res. 2009; 69: 656-62.

10. Guo $\mathrm{H}, \mathrm{Gu} \mathrm{F}, \mathrm{Li} \mathrm{W}$, et al. Reduction of protein kinase $\mathrm{C} \zeta$ inhibits migration and invasion of human glioblastoma cells. J Neurochem. 2009; 109: 203-13.

11. Seto KKY, Andrulis IL. Atypical Protein Kinase C Zeta: Potential Player in Cell Survival and Cell Migration of Ovarian Cancer. PLoS ONE. 2015; 10: e0123528.

12. Butler AM, Scotti Buzhardt ML, Li S, et al. Protein Kinase C Zeta Regulates Human Pancreatic Cancer Cell Transformed Growth and Invasion through a STAT3-Dependent Mechanism. PLoS ONE. 2013; 8: e72061.

13. Kato S, Akimoto K, Nagashima $Y$, et al. aPKClambda/iota is a beneficial prognostic marker for pancreatic neoplasms. Pancreatology. 2013; 13: 360-8

14. Ma L, Tao Y, Duran A, et al. Control of nutrient stress-induced metabolic reprogramming by PKCzeta in tumorigenesis. Cell. 2013; 152: 599-611.

15. Lee H, Park M, Shin N, et al. High mobility group box-1 is phosphorylated by protein kinase $\mathrm{C}$ zeta and secreted in colon cancer cells. Biochem Biophys Res Commun. 2012; 424: 321-6.

16. Ichikawa $\mathrm{Y}$, Nagashima $\mathrm{Y}$, Morioka $\mathrm{K}$, et al. Colorectal laterally spreading tumors show characteristic expression of cell polarity factors, including atypical protein kinase $\mathrm{C}$ lambda/iota, E-cadherin, beta-catenin and basement membrane component. Oncol Lett. 2014; 8: 977-84.

17. Bell GP, Thompson BJ. Colorectal cancer progression: lessons from Drosophila? Semin Cell Dev Biol. 2014; 28: 70-7.

18. Haggar FA, Boushey RP. Colorectal Cancer Epidemiology: Incidence, Mortality, Survival, and Risk Factors. Clin Colon Rectal Surg. 2009; 22: 191-7.

19. Wang X, Chuang HC, Li JP, et al. Regulation of PKC-theta function by phosphorylation in T cell receptor signaling. Front Immunol. 2012; 3: 197.

20. Vasavada RC, Wang L, Fujinaka $Y$, et al. Protein Kinase C- $\zeta$ Activation Markedly Enhances $\beta$-Cell Proliferation An Essential Role in Growth Factor-Mediated $\beta$-Cell Mitogenesis. Diabetes. 2007; 56: 2732-43.

21. Hirai T, Chida K. Protein kinase Czeta (PKCzeta): activation mechanisms and cellular functions. J Biochem. 2003; 133: 1-7.

22. Compton C, Byrd D, Garcia-Aguilar J, et al. AJCC cancer staging manual. Chapter. 2010; 14: 143-64.

23. Allred D, Harvey JM, Berardo $\mathrm{M}$ et al. Prognostic and predictive factors in breast cancer by immunohistochemical analysis. Modern Pathol. 1998; 11: 155-68.

24. Nazarenko I, Jenny M, Keil J, et al. Atypical protein kinase C zeta exhibits a proapoptotic function in ovarian cancer. Mol Cancer Res. 2010; 8: 919-34.

25. Mustafi R, Cerda S, Chumsangsri A, et al. Protein Kinase- $\zeta$ Inhibits Collagen I-Dependent and Anchorage-Independent Growth and Enhances Apoptosis of Human Caco-2 Cells. Mol Cancer Res. 2006; 4: 683-94.

26. Paul A, Gunewardena $S$, Stecklein $S$, et al. PKC $/$ r signaling promotes triple-negative breast cancer growth and metastasis. Cell Death Differ. 2014; 21: 1469-81.

27. Tejeda-Muñoz N, González-Aguilar H, Santoyo-Ramos P, et al. Glycogen Synthase Kinase $3 \beta$ Is Positively Regulated by Protein Kinase Ç-Mediated Phosphorylation Induced by Wnt Agonists. Mol Cell Biol. 2016; 36: 731-41.

28. Jiang YH, Lupton JR, Chapkin RS. Dietary fish oil blocks carcinogen-induced down-regulation of colonic protein kinase C isozymes. Carcinogenesis. 1997; 18: 351-7.

29. Clark AS, West KA, Blumberg PM, et al. Altered protein kinase C (PKC) isoforms in non-small cell lung cancer cells. Cancer Res. 2003; 63: 780-6.

30. Kim JY, Valencia T, Abu-Baker S, et al. c-Myc phosphorylation by PKCל represses prostate tumorigenesis. Proc Natl Acad Sci U S A. 2013; 110: 6418-23.

31. Yin J, Liu Z, Li H, et al. Association of PKCzeta expression with clinicopathological characteristics of breast cancer. PLoS One. 2014; 9: e90811.

32. Pu YS, Huang CY, Chen JY, et al. Down-regulation of PKCzeta in renal cell carcinoma and its clinicopathological implications. J Biomed Sci. 2012; 19: 39.

33. Takagawa R, Akimoto K, Ichikawa $Y$, et al. High expression of atypical protein kinase $C \lambda / \imath$ in gastric cancer as a prognostic factor for recurrence. Ann Surg Oncol. 2010; 17: 81-8.

34. Imamura N, Horikoshi $\mathrm{Y}$, Matsuzaki $\mathrm{T}$, et al. Localization of aPKC lambda/iota and its interacting protein, $\mathrm{Lgl}$, is significantly associated with lung adenocarcinoma progression. Tokai J Exp Clin Med. 2013; 38: 146-58.

35. Newton AC. Protein kinase C: structural and spatial regulation by phosphorylation, cofactors, and macromolecular interactions. Chem Rev. 2001; 101: 2353-64.

36. Cohen EE, Lingen MW, Zhu B, et al. Protein kinase $\mathrm{C}$ zeta mediates epidermal growth factor-induced growth of head and neck tumor cells by regulating mitogen-activated protein kinase. Cancer Res. 2006; 66: 6296-303. 